\title{
Urban spatial structure, transport-related emissions and welfare *
}

\author{
Laurent Denant-Boemont $\ddagger_{\text {Carl Gaigné }}^{\ddagger}$ Romain Gatés
}

October 26, 2016

\begin{abstract}
In this paper, we study the effects of urban design on pollution and welfare. We build a theoretical model of residential choices with pollution externalities arising from commuting, where the size of the central business district (CBD) and the demand for housing are endogenous. We show that a polycentric city is desirable from welfare and ecological perspective, provided that travel speed and/or the number of roads directly connected with the CBD are sufficiently high. The spatial extension of cities remains the critical variable to curb transport-related urban pollution.
\end{abstract}

Keywords: Urban form; Housing; Travel speed; Carbon emissions; Welfare. JEL Classification: Q53; R14; R21

${ }^{*}$ The authors thank seminar and conference participants at University of Barcelona, University of Besançon, University of Rennes1, and UMR SMART for their comments and suggestions.

†Université de Rennes1, CNRS, UMR6211 CREM, 35000 Rennes (France).

‡INRA, UMR1302 SMART, 35000 Rennes (France) and Université Laval, CREATE, Québec (Canada).

$\S$ Université de Rennes1, CNRS, UMR6211 CREM, and INRA, UMR1302 SMART, 35000 Rennes (France).

ฯ Corresponding author: Romain GATE, 7, place Hoche, 35065 Rennes Cedex (France).

Email: romain.gate@univ-rennes1.fr 


\title{
Urban spatial structure, transport-related emissions and welfare *
}

\author{
Laurent Denant-Boemont† Carl Gaigné; Romain Gaté
}

January 23, 2018

\begin{abstract}
In this paper, we study the effects of urban design on pollution and welfare. We build a theoretical model of residential choices with pollution externalities arising from commuting, where the location of jobs within the city and the demand for housing are endogenous. We show that a polycentric city is desirable from welfare and ecological perspective, provided that travel speed and/or the number of roads directly connected with the city center are sufficiently high. The spatial extension of cities remains the critical variable to curb transport-related urban pollution.

Keywords: Urban form; Housing; Travel speed; Carbon emissions; Welfare.
\end{abstract}

JEL Classification: Q53; R14; R21

${ }^{*}$ The authors thank seminar and conference participants at the University of Barcelona, University of Besançon, University of Rennes 1, and UMR SMART for comments and suggestions.

†Université de Rennes 1, CNRS, UMR6211 CREM, 35000 Rennes (France).

†INRA, UMR1302 SMART, 35000 Rennes (France) and Université Laval, CREATE, Québec (Canada).

§Université de Rennes 1, CNRS, UMR6211 CREM, and INRA, UMR1302 SMART, 35000 Rennes (France).

ฯ Corresponding author: Romain GATE, 7, place Hoche, 35065 Rennes Cedex (France).

Email: romain.gate@univ-rennes1.fr 


\section{Introduction}

According to the Department of Economic and Social Affairs of the United Nations (United Nations, 2014), the global urban population has exceeded the rural population since 2007, amounting to 4 billion persons in 2014. Moreover, forecasts are consistent with skyrocketing urban growth in which $66 \%$ of the world population will live in an urban area by 2050 . A striking feature of urban development is that the average floor space per capita tends to increase strongly and the spatial extension of a city increases more than proportionally with population size. For instance, the average living space per capita increased by $80 \%$ in the US between 1975 and 2005 (Calwell, 2010 and Xue et al., 2014). A similar trend is also observed in European countries (Naess and Vogel, 2012) and OECD countries, where the average dwelling size increased by $10 \%$ between 1990 and 2004 (Birol, 2007). One consequence of the growing urban population and housing size per inhabitant is the spread of urban areas into rural areas (urban sprawl) in such a way that the spatial size of cities rises more than proportionally with their number of inhabitants. For example, the land allocated to residential areas increased by $48 \%$ between 1976 and 1992 in the US, while the urban population increased by $18 \%$ (Overman et al., 2008). ${ }^{1}$ Hence, traveled distances within urban areas rise strongly when the urban population grows because the land area assigned to these cities expands. As a consequence, an important drawback of urbanization is that it positively affects the level of greenhouse gas (GHG) emissions through the growth of the energy services required for lighting, heating, and cooling (Hoornweg et al., 2010), but also coming from increasing traffic demand (Hickman and Banister, 2014 ; Litman, 2015).

Technological progress and increasing motor efficiency are likely to be insufficient to curb the pollution level associated with the transport of people within cities (European Environment Agency, 2007). Regarding technological progress and fuel efficiency, Larson et al. (2012) recall that increased fuel efficiency is partly offset by a "rebound" effect in which driving increases, due to a latent demand effect. For instance, Sorrel (2007) gives empirical evidence for this rebound effect, meta-analysis suggesting a value between 10 to $30 \%$ for it. Goulden et al. (2014) also emphasize that absolute decoupling between transport and emissions could only come from widespread electrification of vehicles, which should be very costly and does not solve indirect emissions issues. In France, similar evidence of a rebound effect had been provided by Levy and Le Jeannic (2011). Between 1990 and 2007, technological gains enable a decrease of $13.2 \%$ of $\mathrm{CO}_{2}$ emissions coming from private vehicles if the total distance traveled by workers would be constant. At the same time, average trip distance and population size have increased more rapidly than technological gains, offsetting it. The total evolution of $\mathrm{CO}_{2}$ emissions stemming from private cars had finally increased from $10 \%$ during that period. Another problem related to better energy efficiency and decrease in commuting costs is provided by Brueckner (2011), as empirical evidence suggests that the elasticity of urban area land to commuting cost could be between -0.3 and 0 , which suggests that fuel efficiency improvements causing a decrease in commuting costs could entail

\footnotetext{
${ }^{1}$ As suggested by Rode and Floater (2014), long-run analysis of population densities in cities suggests that there are certain trends towards de-densification. By using a representive sample of cities in developed countries, Angel et al., (2005) estimated that while urban populations grew approximatly 5 per cent between 1990 and 2000, their built-up area increased by 30 per cent. Angel et al. (2005) also observed that average densities decline by 22 per cent during the same period.
} 
increasing commuting distances.

As improvements in energy efficiency are likely to be insufficient to stabilize the transportrelated pollution in cities, policy makers and urban planners need to consider other initiatives to mitigate urban pollution ${ }^{2}$. As noted by Floater et al., (2014) and Burgalassi and Luzzati (2015), the environmental impacts of urbanization may depend on differences in spatial structures and their dynamics. In other words, urban forms play a key role in the carbon emissions. For instance, for a given population, higher population density is associated with lower levels of emissions (Glaeser and Kahn, 2010; Zheng et al., 2011). By increasing the share of public transport, high density induces relatively low carbon emissions. In addition, an important factor of transport demand is the imbalance of housing vs. jobs, that is, the distance between dwellings and workplaces (Bento et al., 2005). Longer commuting flows are caused by the development of jobs in the inner city while workers live farther away from the city center. The decentralization of jobs through the creation of subcenters within a city (i.e., the formation of a polycentric city) may also be a strategy to reduce the amount of commuting and improve global welfare (Gaigné et al., 2012). Public authorities may control the intra-city distribution of firms to decrease the average distance traveled by workers. ${ }^{3}$

From the ecological and economic efficiency viewpoints, the polycentric city is seductive at a first glance (Anas et al., 1998; Bertaud, Lefèvre and Yuen, 2011). Because there are many job centers, the average distance between a household's residential place and workplace is expected to be shorter than the corresponding distance in a monocentric city. Hence, the development of secondary business districts would decrease the total distance traveled by workers and, in turn, shrink carbon emissions due to a lower traffic volume and land rents (see Gaigné et al., 2012; Legras and Cavailhès, 2016). However, when assessing the impact of decentralization of jobs on carbon emissions, the existing literature has failed to address a major issue. Indeed, the housing size is assumed to be given, so the population density is constant. Instead, the effects of urban spatial structure should be analyzed within a framework in which housing size is endogenously determined in response to the location of jobs and land rents. Urban housing size cannot be considered independently from the urban form. ${ }^{4}$

The objective of this paper is to assess the impacts of job decentralization on transportrelated pollution and welfare when housing size reacts to a change in workplace location. Some studies provide the theoretical micro-foundations of the formation of polycentric cities when the housing size is endogenous (Fujita and Ogawa, 1982; Anas and Kim, 1996; Lucas and Rossi-Hansberg, 2002). However, they do not study the impact of the emergence of polycentric cities on urban pollution and welfare. To reach our goal, we develop a simple model in which housing demand and job decentralization are endogenous. However, our model delivers full analytical solutions and captures in a simple way (i) the fact that pop-

\footnotetext{
${ }^{2}$ An important issue to tackle the problem between energy consumption, emissions and urbanization, not discussed in this paper, is about optimal taxation of externalities coming from urban sprawl, e.g., traffic congestion and pollution. These dimensions are discussed, among others, by Larson et al., (2012) and Borck and Brueckner, (2016).

${ }^{3}$ The decentralization of jobs in a few subcenters within cities is observed in London, Paris, Los Angeles and even Mexico, which have become polycentric cities in the past few decades (Storper, 2013).

${ }^{4}$ Legras and Cavailhès (2016) consider three different lot sizes. However, the authors assume that lot sizes are exogenously given and disregard their effects on welfare.
} 
ulation density is higher in the central city than at the city outskirts, in accordance with the empirical evidence; (ii) the fact that the share of jobs established in subcenters grows with city size and lowers commuting costs and (iii) the basic trade-off between long/short commutes, low/high land rents, and high/low housing size.

We argue that developing subcenters within cities, that is, evolution toward a polycentric structure, is not necessarily the best strategy to reduce commuting flows and to improve welfare. Our analysis relies on the following trade-off. On the one hand, for a given population density, the average distance traveled by workers shrinks when the city shifts from a monocentric structure to a polycentric configuration. Hence, for a given housing size, job decentralization within cities decreases carbon emissions by making commuting trips shorter. This is true as long as the city border remains unchanged. On the other hand, the average housing size would increase when jobs are located on the edge of the city since the average price of land diminishes. As a consequence, the city border expands away from the city center and the average commuting distance may rise. The increasing housing demand may therefore counteract the positive effects of the emergence of secondary business districts on commuting distances and carbon emissions.

Indeed, the net effect of this development on welfare depends on the characteristics of the transportation network within the city. More precisely, when housing size adjusts to urban forms through a change in land rents, a polycentric city is not desirable from welfare and ecological viewpoints when average travel speed and/or the number of roads directly connected with the inner city are low. More generally, our results show that the evaluation of urban policy effect on pollution emission needs to consider the long-run adjustments in housing size and density. In a different context, Arnott (1979) and Borck (2016) find that the impacts of transport policies and building height restrictions differ when housing size adjusts.

Our analysis can also explain why the effects of employment decentralization in polycentric metropolitan areas on the patterns of commuting differ across empirical studies. For example, Giuliano and Small (1993) find that the decentralization of jobs shortens commuting trips, whereas Aguilera (2005) shows that polycentric cities cause potentially higher commuting distances than monocentric cities. Therefore, the spatial extension of cities remains a critical variable to curb transport-related pollution.

The paper is organized as follows. In the first section, we describe our model. We discuss in Section 3 the levels of welfare and pollution when the city is monocentric or when the city is polycentric in Section 4. Section 5 provides extensions of our framework to check the robustness of our main results. The last section concludes.

\section{A simple model}

Our framework extends the model developed in Cavailhès et al., (2007). Lot size is endogenously determined within a city endowed with $L>0$ workers. They are free to choose their residential location and their workplace and can consume two goods: land, which is used as a proxy for housing, and the numéraire ${ }^{5}$. Urban land is exclusively devoted to residential purposes - firms do not use land and therefore do not compete for it - and transportation

\footnotetext{
${ }^{5}$ For simplicity, we assume that land is owned by absentee landlords.
} 
capacity is supplied without land. Workers travel only for commuting purposes ${ }^{6}$. We also assume that there is no vacant land at the residential equilibrium.

The city is endowed with $m \geq 1$ residential areas, which are connected only to the central business district (CBD). Formally, the city is described by $m$ one-dimensional halflines sharing the same initial point $x=0$. Distances and locations to the CBD are expressed by the same variable $x$ measured from 0 . Hence, the city is characterized by a hub-and-spoke transportation network in which $m$ is also the number of spokes. Such a spatial representation of the city allows us to study the role of the transportation network structure in the efficiency of urban forms. The city is assumed to be symmetric around the CBD. The limit of the city in each residential area is given by $y$ so that the total residential area is my. Firms are located either in the CBD or in a secondary business district (SBD). Each residential area/spoke hosts at most one SBD. The location of the $\mathrm{SBD} z_{P}$ along each spoke is determined endogenously.

Workers share the same quasi-linear utility function, given $\mathrm{by}^{7}$

$$
U=q+\sqrt{h}-\mu E,
$$

where $q$ is the consumption of the numéraire, $h$ is the consumption of housing floor space, and $E$ is a negative externality related to the total emission of pollution at the city level generated by commuting flow. The parameter $\mu$ captures the magnitude of the disutility arising from urban pollution. Our utility function assumes that the demand for housing does not vary directly with income. As we will see below, the bid rents offered by workers depend on income due to commuting time such that income affects a worker's residential choice.

We consider that $E=\varepsilon C$, where $C$ is the sum of the distance traveled by workers and $\varepsilon$ is the amount of carbon dioxide generated by one unit of distance traveled by a worker. The value of $\varepsilon$ depends on the technology used (less-fuel-intensive and non-fuel vehicles, ecodriving and cycling) and on the commuting mode (public transportation versus individual cars). For simplicity, we assume that $\varepsilon$ is a given parameter that is independent from city size and compactness ${ }^{8}$. Because the terms $\mu$ and $\varepsilon$ will always appear together throughout this paper, we find it convenient to set $\zeta \equiv \varepsilon \times \mu$.

The time constraint of a worker located at $x$ is given by

$$
1=\ell+\tau\left|x-z_{i}\right|
$$

where $\ell$ is the amount of labor time and $\tau\left|x-z_{i}\right|$ is commuting time from her residential location $x$ to the location of the business district $z_{i}$ with $z_{i}=0$ (resp., $z_{i}=z_{P}$ ) if her job is located in the CBD (resp., SBD) ${ }^{9}$. Hence, $\tau>0$ is the travel time per unit of distance. As a consequence, the parameter $\tau$ can also be interpreted as the inverse of average travel speed in the city. The budget constraint of a worker located at $x$ can be written as follows:

$$
\omega_{i} \ell(x)=q+\frac{R(x)}{\delta(x)} h(x)+t(x),
$$

${ }^{6}$ We neglect shopping and leisure trips in that framework. According to CGDD (2010) for France and AASHTO (2013) for the US, commuting trips represent approximately 1/4 of total local trips for households.

${ }^{7}$ Using a Cobb-Douglas utility function does not qualitatively change our results.

${ }^{8}$ Because collective forms of transport are more viable in larger and/or more compact cities, one would expect $\varepsilon$ to be a decreasing function of city size and/or compactness. Although we treat $\varepsilon$ as a parameter, we will discuss what our results become when $\varepsilon$ varies.

${ }^{9}$ In this context, time granted to leisure activities is excluded without loss of generality. 
in which $\omega_{i}$ is the wage rate per time unit with $\omega_{i}=\omega_{0}$ (resp., $\omega_{i}=\omega_{P}$ ) if her job is located in the CBD (resp., SBD). The wage rates are treated as exogenous parameters and could vary across business districts within the city, in accordance with empirical evidence (Timothy and Wheaton, 2001). The parameter $t(x)$ represents the monetary costs of commuting between one's workplace and one's residence ${ }^{10}$, and $R(x)$ is the land rent at $x$. Because $\delta(x)$ is the housing floor space per unit of land at distance $x, R(x) / \delta(x)$ is the price per floor space unit paid by a consumer living at $x$. Accordingly, in a competitive market framework, the household that makes the highest bid gets the housing at $x$, in line with Alonso (1964). Without loss of generality, we assume that $t(x)=0$ and $\delta(x)=1$. Hence, workers face a trade-off between the level of land rent to pay, the commuting costs (measured as the opportunity cost of time) and the size of their housing.

Utility (1) maximization under the budget constraint (3) and the time constraint (2) leads to the individual demand for housing

$$
h(x)=\frac{1}{4 R(x)^{2}} .
$$

As expected, the housing size at $x$ decreases with the price $R(x)$ paid by a consumer to reside at $x$. It follows that we abstract from a direct effect of income on the demand for housing. This point is discussed below. As a result, the indirect utility is given by

$$
V(x)=\omega_{i}\left(1-\tau\left|x-z_{i}\right|\right)+\frac{1}{4 R(x)}-\zeta C,
$$

in which we have plugged (3), (2) and (4) into (1). Note that high land rents induce low housing size per resident at each location, given the exogenous supply of housing floor space. The indirect utility depends on the pollution externality associated with commuting flows $\zeta C$, as well as the income net of commuting time cost and land rents $\left(\omega_{i}\left(1-\tau\left|x-z_{i}\right|\right)+1 /[4 R(x)]\right)$. The latter term is called private welfare because it corresponds to the consumption of private goods. Private welfare is driven by the urban spatial structure, which is determined endogenously regarding the locations of SBDs and city limit.

\section{The monocentric city}

We begin with a spatial structure commonly used in the urban economics literature: the monocentric city. There is a single business district (the CBD). Workers choose their living place within the city to maximize their utility, such that their residential choice depends on the price paid for housing, the size of housing and commuting time. At the city equilibrium, each worker maximizes her indirect utility (5), and markets clear. The opportunity cost of land is $R_{A}$ at the fringe. The equilibrium land rent at each location is given by $R(x)=$ $\max \left\{\Psi(x), R_{A}\right\}$, where $\Psi(x)$ is the bid rent. Given $V(x)$, the bid rent must solve $\partial V(x) / \partial x=$ 0 . At the city equilibrium, all workers reach the same indirect utility level. Accordingly, the distribution of urban dwellers is such that $V(x)=V(y)$ regardless of $x$ and $R(y)=R_{A}$. Hence,

$$
V(y)=\omega_{0}-\omega_{0} \tau y+\frac{1}{4 R_{A}}-\zeta C .
$$

\footnotetext{
${ }^{10}$ Fuel, maintenance and insurance costs of car owners.
} 
and the bid rent function is given by

$$
\Psi(x)=\frac{R_{A}}{1-4 \omega_{0} \tau(y-x) R_{A}},
$$

so that the individual demand for housing at the equilibrium is given by

$$
h(x)=4\left[\frac{1}{4 R_{A}}-\omega_{0} \tau(y-x)\right]^{2} .
$$

In equilibrium, the land rent depends on the housing floor space per unit of land, the opportunity cost of land, the wage rate, the time spent per unit of distance for a commuting trip within the city and the location $x$. The equilibrium land rent decreases with respect to the distance $x$ from the CBD. Meanwhile, the housing demand increases. As each household reaches the same utility whatever her/his location $x$, there is a trade-off between the rent cost and housing size. Notice that the bid rent equals the opportunity cost of land $R_{A}$ when a worker is located at the city border $(x=y)$. The size of housing achieves its maximal value at the city limit.

The city border $y_{M}$ solves the total population constraint given by

$$
L=m \int_{0}^{y_{M}} l(x) \mathrm{d} x
$$

in which $l(x)$ is the population density at $x$ with $l(x)=1 / h(x)$. Solving (9) by using $l(x)=1 / h(x)$ and (8) implies that the equilibrium city border is given by

$$
y_{M}=\frac{1}{4 R_{A}} \frac{L / m}{R_{A}+\omega_{0} \tau L / m},
$$

when all jobs are located in the CBD (see Appendix A for the details). It is straightforward to check that the city border decreases with respect both to income $\omega_{0}$ and commuting time $\tau$ as the opportunity cost of travel time increases. Under this configuration, the workers have an incentive to live close to the CBD, rising the land rent and, in turn, reducing the average size of housing. Increasing the number of residential areas around the CBD $(m)$ makes the city more compact, as the city border shrinks.

Inserting (10) in (6) yields the individual welfare in equilibrium

$$
V_{M}=\omega_{0}+\frac{1}{4 R_{A}}\left(1+\frac{\omega_{0} \tau L}{m R_{A}}\right)^{-1}-\zeta C_{M}
$$

when the city is monocentric, where $C_{M}$ is the total distance traveled by commuters within the city with

$$
C_{M}=\frac{m}{4 \omega_{0}^{2} \tau^{2}}\left[\ln \left(1+\frac{\omega_{0} \tau L}{m R_{A}}\right)-\frac{\omega_{0} \tau L}{m R_{A}+\omega_{0} \tau L}\right] .
$$

The details of the calculations are reported in Appendix B. Some standard calculations reveal that an increase in the population size increases total distance traveled by workers as the city border increases. As households face higher land rents when the city limit expands (see (7)), 
the demand for housing diminishes near the city center. As a result, the population density increases, even if a fraction of workers relocate farther away from the CBD. However, the individual welfare decreases with population size as long as the wage rate remains unchanged. Having a growing population therefore has two negative effects. First, it reduces private welfare because the land rent increases. Second, it induces longer travel distances and more pollution, which negatively affects the global welfare. ${ }^{11}$

It should be noted that, if a lower travel speed (or a higher $\tau$ ) generates a more compact city (i.e., the distance traveled by the urban workers living furthest away decline), the effects are ambiguous on welfare $V_{M}$ when transport-related pollution affects utility. As in the standard urban model, the net income of workers decreases with commuting time without pollution. In contrast, the total distance traveled by commuters decreases with commuting cost $\left(\mathrm{d} C_{M} / \mathrm{d} \tau<0\right.$, see Appendix $\left.\mathrm{B}\right)$. Indeed, workers have a clear incentive to move closer to the city center when commuting cost increases, as households dislike spending time commuting. In this case, the average size of housing decreases, implying a fall in commuting flows and, in turn, in transport-related emissions.

The number of roads directly connected to the CBD $(m)$ may also be a tool to improve the efficiency of the city. A higher $m$ reduces the distance traveled by the urban worker living furthest away ( $y_{M}$ decreases). For a given housing size, more roads connected to the CBD make the city more compact and reduce pollution. However, when the housing size adjusts, the effect is ambiguous on $C_{M}$. Indeed, the total residential area of the city (measured by $\left.m y_{M}\right)$ or the average size of housing increases with the number of roads, which implies that the total distance traveled by commuters increases $\left(\mathrm{d} C_{M} / \mathrm{d} m>0\right.$, see Appendix B). In contrast, private welfare increases with the number of residential areas.

We summarize our results as follows,

Proposition 1. Assume a monocentric city. Higher travel speed (lower $\tau$ ) or more roads directly connected to the $C B D$ (higher $m$ ) improves private welfare but magnifies the negative externality arising from transport-related emissions.

\section{The polycentric city}

In this section, we determine the spatial equilibrium when a share of firms can be located in the SBDs. Individuals choose their workplace (CBD or SBD) for given wages and land rents. At the spatial equilibrium, no worker wants to change her working place or residence. The distribution of workers is such that $\mathrm{d} V(x) / \mathrm{d} x=0$. Both the CBD and the SBDs are surrounded by residential areas occupied by consumers. All the land is used for housing over the interval $[0, y]$. Denote by $\widehat{z}$ the right endpoint of the residential area formed by individuals working in the CBD (or, equivalently, the left endpoint of the residential area formed by individuals working in the SBD, see Figure 1). We assume, without loss of generality, that the SBD is located in the middle point of the residential area in which the individuals work in the SBD. There is no reason why the distribution of workers around $z_{p}$ should be not

\footnotetext{
${ }^{11}$ Note that the population increase has no effect on wage rates and on the diversity of goods available in the city.
} 
symmetric. Hence,

$$
z_{P}=\frac{\widehat{z}+y_{P}}{2}
$$

Therefore, the bid rents at $y_{P}$ and $\widehat{z}$ are equal and reach the opportunity cost of land $R_{A}$.

Size of SBDs, housing size and city limit. The worker living at $\widehat{z}$ is indifferent between working in the $\mathrm{CBD}$ or in the SBD, which implies

$$
\omega_{0}(1-\tau \widehat{z})=\omega_{P}\left[1-\tau\left(z_{P}-\widehat{z}\right)\right]
$$

We assume that $\omega_{P}=\mu \omega_{0}$ with $0<\mu<1$, which measures the magnitude of the spread between the two business districts. Empirical evidence shows that firms are able to pay lower wages in SBDs. For example, Timothy and Wheaton (2001) report large variations in wages according to intra-urban location $(15 \%$ higher in central Boston than in outlying work zones, $18 \%$ between central Minneapolis and the fringe counties). According to Baum-Snow and Pavan (2012), agglomeration economies arise mainly within the central city, which explains why the wage rate is higher in the CBD. In addition, even though the wage rate is lower in the SBD than in the CBD, the former remains attractive because the wage net of commuting cost (for the worker) may be higher in the SBD than in the CBD.

Hence, the location of the worker being indifferent between working in the CBD or in the $\mathrm{SBD}$ located at a distance $z_{P}$ from the CBD is given by,

$$
\widehat{z}\left(y_{P}\right)=\frac{2(1 / \mu-1)+\tau y_{P}}{\tau(2 / \mu+1)},
$$

in which we have inserted $\omega_{P}=\mu \omega_{0}$ and (13) in (14). It follows that $\widehat{z}$ increases with $1 / \mu$. As expected, higher wage rates in the CBD than in the SBD make the former more attractive. The size of the CBD (measured as the number of individuals working in the CBD) increases at the expense of the size of the SBDs. Conversely, a wage decline in the CBD leads to urban sprawl as long as the wage rate in the SBDs is unchanged. Indeed, as the CBD becomes less attractive in terms of relative wage, the demand for housing decreases near the CBD and rises near the SBD. There exists a limit value of $\omega_{P} / \omega_{0}(\underline{\mu})$ below which the city is always monocentric, as given by $\widehat{z}(\underline{\mu})=y_{P}$ or, equivalently, $\underline{\mu}=\overline{1}-\tau y_{P}$. Hence, a polycentric city emerges if and only if $\mu>1-\tau y_{P}$. The size of the SBD in terms of jobs grows with $\mu$ and reaches its maximum size when $\mu=1$ (so that $\widehat{z}=y_{P} / 3$ ). In other words, $y_{P}>\widehat{z} \geq y_{P} / 3$.

Further, when the city is polycentric, the equilibrium land rent is given by $R_{P}(x)=\max \left\{\Psi_{0}(x), \Psi_{P}(x), R_{A}\right\}$ where $\Psi_{0}(x)$ (resp., $\Psi_{P}(x)$ ) is the bid rent of individuals working in the CBD (resp., SBD). As $\partial V(x) / \partial x=0$, the bid rents around the CBD and the SBDs are given by, respectively,

$$
\Psi_{0}(x)=\frac{R_{A}}{1-4 \omega_{0} \tau(\widehat{z}-x) R_{A}} \quad \text { and } \quad \Psi_{P}(x)=\frac{R_{A}}{1-4 \omega_{P} \tau\left[\frac{y_{P}-\widehat{z}}{2}-\left|z_{P}-x\right|\right] R_{A}} .
$$

The bid rents decrease with the distance to the business districts (see Figure 1). As a result, the equilibrium housing demands for individuals working in the CBD and in the SBD are respectively given by

$$
h_{0}(x)=4\left[\frac{1}{4 R_{A}}-\omega_{0} \tau(\widehat{z}-x)\right]^{2} \quad \text { and } \quad h_{P}(x)=4\left[\frac{1}{4 R_{A}}-\omega_{P} \tau\left(\frac{y_{P}-\widehat{z}}{2}-\left|z_{P}-x\right|\right)\right]^{2} .
$$




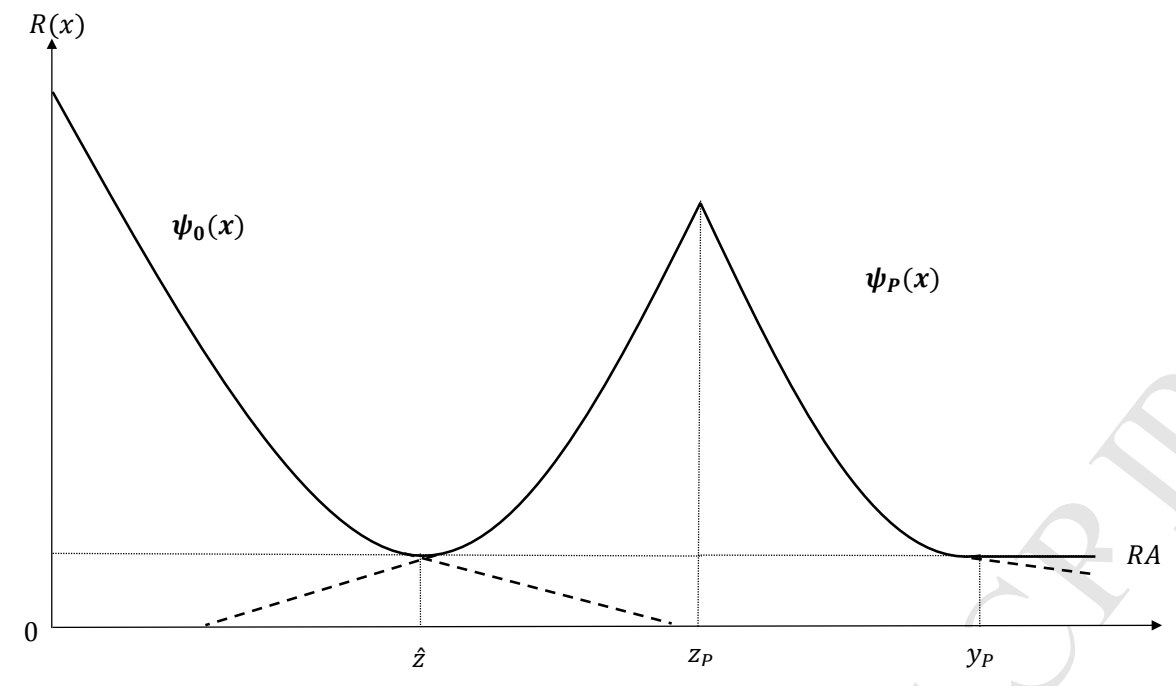

Figure 1: Upper enveloppe of the bid rents in equilibrium and location of CBD limit $\widehat{z}$, and limit $y_{P}$ of the polycentric city.

It is straightforward to check that land rent decreases and the housing size grows when the city becomes polycentric, whereas the city boundary is unchanged (see Appendix C). In addition, the bid rents and housing size remain identical for all $x \in\left[z_{P}, y_{P}\right]$ when a SBD is created if $y_{P}$ is unchanged. Since the land rent declines and demand for housing rises at distances lower than $z_{P}$, the urban fringe must move outward when the economy shifts from a monocentric city to a polycentric city. As the population constraint is non-linear, the expression of the equilibrium city border is implicitly defined. In Appendix D, we show that the city limit is such that

$$
\frac{4 R_{A}^{2} \widehat{z}\left(y_{P}\right)}{1-4 \omega_{0} \tau \widehat{z}\left(y_{P}\right) R_{A}}+\frac{4 R_{A}^{2}\left[y_{P}-\widehat{z}\left(y_{P}\right)\right]}{1-2 \mu \omega_{0} \tau\left[y_{P}-\widehat{z}\left(y_{P}\right)\right] R_{A}}=\frac{L}{m} .
$$

Hence, equations (15) and (17) allow us to determine the equilibrium city limit and the equilibrium size of the CBD (in terms of jobs). Notice that if $z=y_{P}$, then we fall back on the monocentric configuration and $y_{P}=y_{M}$. As a result, if a city becomes polycentric, then $\widehat{z}<y_{M}$, so that the population constraint can hold. It is also straightforward to check that $y_{P}>y_{M}$ for all $0<\widehat{z}<y_{M}{ }^{12}$. Hence, as the average land rent decreases, households receive higher utility from larger housing, which explains the lower average population density ${ }^{13}$. Consequently, the housing size effect causes a shift in the city limit $y_{M}$. Notice that workers reside gradually closer to the $\mathrm{CBD}$ in tinier housing because of their higher value of time when the wage rate in the CBD increases $(1 / \mu$ increases $)$.

We summarize our results as follows,

\footnotetext{
${ }^{12}$ According to $(17)$, we have $y(z=0)>y\left(z=y_{M}\right)$ and $\left.\frac{\partial y}{\partial z}\right|_{z=0}>0>\left.\frac{\partial y}{\partial z}\right|_{z=y_{M}}$. In addition, $y(z)$ has a single extremum when $z \in\left[0, y_{M}\right]$, which is a maximum.

${ }^{13}$ In their urban energy footprint model (UEFM), Larson et al., (2012) demonstrate that a decrease in housing costs also leads to demand for a larger lot size. The structural density is also decreasing, as in our theoretical model.
} 
Proposition 2. The demand for housing increases when the city moves from a monocentric configuration to a polycentric one for a given city border. Therefore, the city limit moves outward when the city becomes polycentric in equilibrium.

This proposition shows that it is crucial to capture long-run adjustments in the urban housing market in order to study the effect of urban forms on welfare and pollution. Because the city border increases, the effects of a relocation of jobs farther away from the CBD on commuting distances and, in turn, on welfare are ambiguous. Indeed, we have

$$
V_{P}-V_{M}=\omega_{0} \tau\left[y_{M}-\frac{\mu}{2+\mu} y_{P}-\frac{2(1-\mu)}{\tau(2+\mu)}\right]-\zeta\left(C_{P}-C_{M}\right)
$$

where we have used (5) for a worker living at the city border in the monocentric city $\left(V_{M}\right)$ and for a worker who is indifferent between working in the CBD and in the SBD in the polycentric city $\left(V_{P}\right)$. In order to disentangle the different effects at work, we first analyze the case where the wage rates in the CBD and the SBDs are equal. Then, in accordance with empirical evidence, we assume that workers receive a higher wage rate in the CBD than in the SBDs.

No wage gap between the CBD and the SBDs. For simplicity, we first consider that $\omega_{P}=\omega_{0}(\mu=1)$ so that $\widehat{z}=y_{P} / 3$. In this case, the housing size grows at sites close to the $\operatorname{CBD}(x \leq \widehat{z})$ and sites located between $\widehat{z}$ and $z_{P}$ when the city becomes polycentric, whereas $y_{P}$ is unchanged. In addition, the bid rents and housing size remain identical for all $x \in\left[z_{P}, y_{P}\right]$ when a SBD is created if $y_{P}$ is unchanged and there is no wage wedge in the city (see Appendix C).

Using the population constraint (17) and $\widehat{z}=y_{P} / 3$, the equilibrium border when the city is polycentric is expressed as follows

$$
y_{P}=\frac{1}{4 R_{A}} \frac{L / m}{R_{A}+\omega_{0} \tau L / 3 m} .
$$

As expected, the city limit expands when jobs relocate in the SBDs since $y_{P}>y_{M}$. The effects of a relocation of jobs farther away from the CBD on commuting distances and welfare are ambiguous. Indeed, the individual welfare is now given by

$$
V\left(y_{P}\right)=\omega_{0}+\frac{1}{4 R_{A}}\left(1+\frac{\omega_{0} \tau L}{3 m R_{A}}\right)^{-1}\left(1-\frac{2 \omega_{0} \tau L}{3 R_{A} m}\right)-\zeta C_{P},
$$

where $C_{P}$ is total commuting distances within a polycentric city (see Appendix $\mathrm{C}$ for details):

$$
C_{P}=\frac{3 m}{4 \omega_{0}^{2} \tau^{2}}\left[\ln \left(1+\frac{\omega_{0} \tau L}{3 m R_{A}}\right)-\frac{\omega_{0} \tau L}{3 m R_{A}+\omega_{0} \tau L}\right] .
$$

Without pollution externality $(\zeta=0)$, it is straightforward to check that private welfare increases when the city becomes polycentric. Job decentralization leads to lower land rents on average and to higher housing size as the maximum distance traveled by a worker declines. Indeed, the maximum distance traveled between a residential location and a workplace is 
given by the commuter living at $\widehat{z}$ or at the city border $y_{P}$. Thus, for an individual working in the $\mathrm{SBD}$, the distance is equal to $\widehat{z}=y_{P}-z_{P}=y_{P} / 3$ when the city is polycentric, whereas the maximum distance equals $y_{M}>y_{P} / 3$ when the city is monocentric. As a result, with no pollution externality, private welfare improves when jobs relocate to the periphery of the city. Indeed, using (22) implies

$$
V_{P}(\zeta=0)-V_{M}(\zeta=0)=\omega_{0} \tau y_{M}\left(1-\frac{1}{3} \frac{y_{P}}{y_{M}}\right)>0 .
$$

It follows that if the city border grows in high proportion $\left(y_{P} / y_{M}\right.$ reaches high values), the gain in private welfare is low.

When pollution externality is considered $(\zeta>0)$, the analysis is more complex, as the total distance traveled by workers can increase or decrease when the city becomes polycentric. In Appendix E, we show that $C_{P}<C_{M}$ and $V_{P}>V_{M}$ if and only if $\omega_{0} \tau L / m R_{A} \equiv \Gamma$ is not too high ${ }^{14}$. The polycentric city makes workers better off if travel speed $(1 / \tau)$ or the number of roads $(m)$ are relatively high in relation to the population size. However, when population size reaches relatively high values $(\Gamma>>1)$, a monocentric city implies a lower total traveled distance and higher welfare than the polycentric city.

The basic intuition is as follows. When the ratio $\Gamma$ faces a steep rise, the city border of the polycentric city increases substantially. Indeed, some standard calculations show that $y_{P} / y_{M}=(1+\Gamma) /(1+\Gamma / 3)$, which increases with $\Gamma$. In other words, when the city becomes polycentric, the city border expands strongly when the opportunity costs of travel time and population size are sufficiently high. In a monocentric city, households are located close to the CBD in tiny housing when the opportunity costs of travel time are high. In a city endowed with several SBDs, even though the value of travel time is high, the average housing size remains relatively high. Indeed, the maximum distance traveled by a worker is much lower in a polycentric city than a monocentric city $\left(y_{P} / 3\right.$ instead of $\left.y_{M}\right)$. As a result, total commuting distances tend to rise strongly in a polycentric city when commuting time $(\tau)$ is high and the number of roads $(m)$ is low. In contrast, the gain in private welfare when the city adopts a polycentric structure is weak when the city limit expands strongly (see (22)). Thus, social welfare increases when the city becomes polycentric, provided that the value of travel time is not too high or that the number of roads directly connected to the CBD is sufficiently high.

The case where $\omega_{P}<\omega_{0}$. We now examine the case where $\omega_{P}=\mu \omega_{0}$ with $0<\mu<1$. In Appendix D, we report the expression of the city border $y_{P}(\mu)$. Several standard calculations reveal that $\mathrm{d} y_{P}(\mu) / \mathrm{d}(1 / \mu)<0$ evaluated at $\mu=1$. A marginal increase of $1 / \mu$ leads to a more compact city as $y_{P}(\mu)$ decreases and approaches the CBD limit $\widehat{z}(\mu)$. Because the CBD is more attractive when $1 / \mu$ increases, the residential areas surrounded the SBDs shrink. The welfare is now given by

$$
V_{P}(\mu)=\omega_{0} \frac{3-\tau y_{P}(\mu)}{2 / \mu+1}+\frac{1}{4 R_{A}}-\zeta C_{p}(\mu)
$$

$14 * *$ This parameter $\Gamma$ represents the ratio between the opportunity cost of commuting time for the whole city population per unit of distance and the land opportunity cost of all roads within the city.** 
in which the expression of $C_{p}(\mu)$ is provided in Appendix F. As the expressions of $y_{P}(\mu)$ and $C_{p}(\mu)$ are highly non-linear, we cannot provide an analytical derivation of these properties. Instead, we present numerical simulations to study the impact of job decentralization on commuting flow and welfare when the wage rate is higher in the CBD than in the SBDs. Different numerical simulations are performed. Under the configuration where $\omega_{P}=\omega_{0}$, the ratio $\omega_{0} \tau L / m R_{A}$ plays a critical role, confirming our main results.

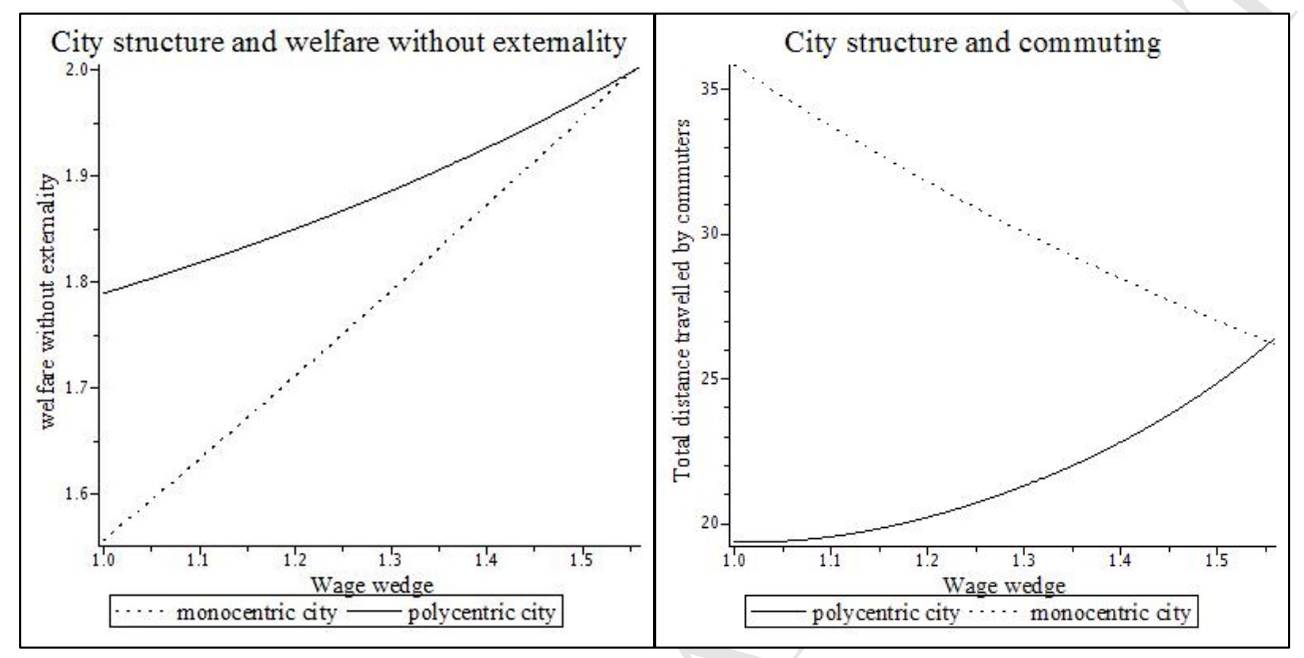

Figure 2: Evolution of private welfare (without pollution externality) with wage gap $(1 / \mu)$ [left-hand side]. Evolution of total commuting distances with wage gap $(1 / \mu)$ [right-hand side]. Case with a low $\Gamma:\left(L=20, \tau=1 / 10, \omega_{P}=1, \delta=1, m=10, R_{A}=1 / 4\right.$. $)$

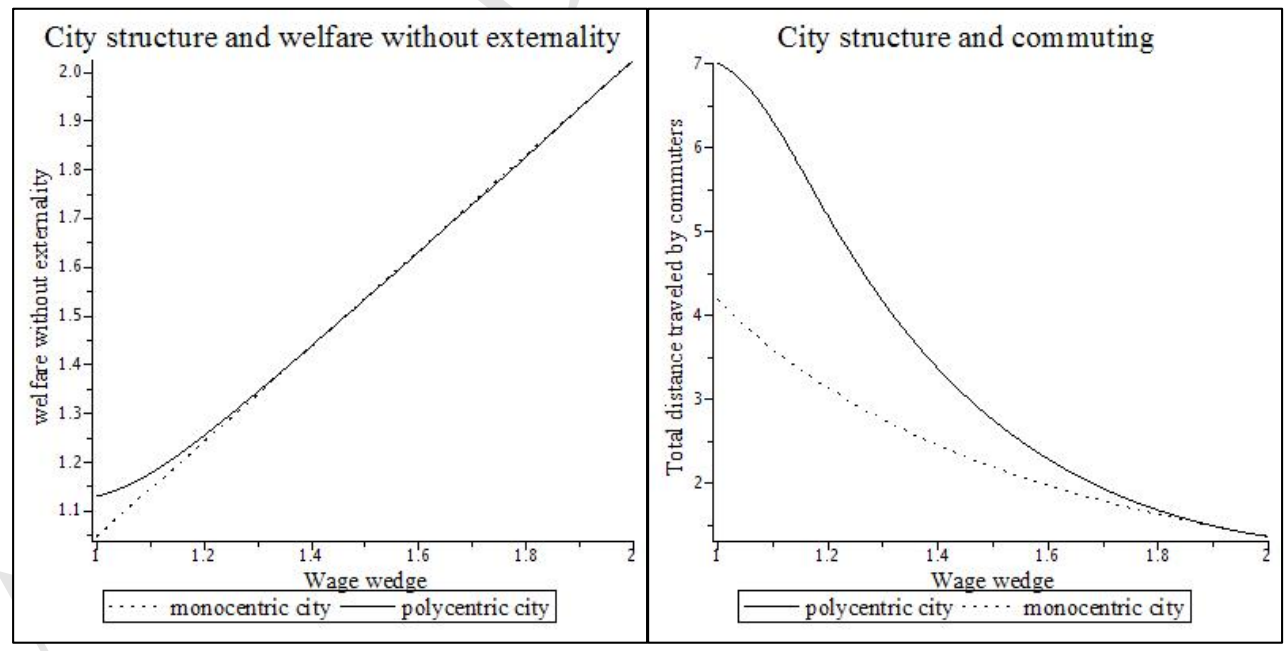

Figure 3: Evolution of private welfare (without pollution externality) with wage gap $(1 / \mu)$ [left-hand side]. Evolution of total commuting distances with wage gap $(1 / \mu)$ [right-hand side]. Case with a high $\Gamma:\left(L=20, \tau=1, \omega_{P}=1, \delta=1, m=2, R_{A}=1 / 4\right.$. $)$

In Figure 2, we select the value of parameters such that $\omega_{0} \tau L / m R_{A}$ is low enough ${ }^{15}$,

${ }^{15}$ We have selected the following values: $L=20, \tau=1 / 10, \omega_{P}=1, \delta=1, m=10$, and $R_{A}=1 / 4$. 
whereas in Figure 3, we consider a case where $\omega_{0} \tau L / m R_{A}$ is high ${ }^{16}$. Our simulations confirm that $C_{P}<C_{M}$ and $V_{P}>V_{M}$ (resp., $C_{P}>C_{M}$ and $V_{P}=V_{M}$ ) when $\omega_{0} \tau L / m R_{A}$ is low (resp., high) enough. We report the figures plotting $C_{P}$ and $C_{M}$ against $1 / \mu$ (from 1 to $1 / \mu$ ), as well as $V_{P}$ and $V_{M}$ when there is no pollution externality $(\zeta=0)$ against $1 / \mu$. It follows that the polycentric city is socially desirable as long as the opportunity cost of travel time is not too high. Whether a polycentric city is an efficient urban form depends on commuting costs, the traffic network, and the relative attractiveness of the CBD. We summarize our results as follows,

Proposition 3. When a city adopts a polycentric configuration instead of a monocentric configuration, transport-related pollution falls and social welfare rises, provided that travel speed and/or the number of roads directly connected to the CBD are sufficiently high. Without pollution externality, the total number of roads $m$ increases horizontally and private welfare increases as long as the maximum traveled distance of commuters is lower than in the monocentric structure.

\section{Discussion}

\subsection{Extending the city vertically}

In the model, we have considered the housing floor space per unit of land $\delta(x)$ (tallness of buildings) to be uniformly distributed across the city $(\delta(x)=1)$. Despite this assumption, population density and land rents are decreasing with distance to jobs as housing demand is endogenous, in accordance with empirical evidence. However, we do not know whether our assumption is restrictive when we study the relationship between urban form and transportrelated pollution. We now assume that the housing supply of floor space per unit of land in residential area around the CBD is given by $1+\Delta_{\delta}$ and is higher than the ones in the residential area around the SBDs i.e., $\Delta_{\delta}>0$. It allows us to capture the fact that building heights are higher near the CBD because land price is higher (Brueckner, 2011). Skyscrapers are commonly build around the CBD. The equilibrium land rent and the housing demands around the CBD and the SBDs have a similar form as previously studied (see Appendix F).

The residential location of the individual who is indifferent between working in the CBD or in the $\mathrm{SBD} \widehat{z}$ is the solution to $V_{0}(\widehat{z})=V_{P}(\widehat{z})$ which is equivalent to

$$
\omega_{0}(1-\tau \widehat{z})+\frac{1+\Delta_{\delta}}{4 R_{A}}=\omega_{P}\left[1-\tau\left(z_{P}-\widehat{z}\right)\right]+\frac{1}{4 R_{A}} .
$$

leading to

$$
\widehat{z}\left(y_{P}\right)=\frac{2(1 / \mu-1)+\tau y_{P}+\frac{\Delta_{\delta}}{2 R_{A} \omega_{P}}}{\tau(2 / \mu+1)}
$$

in which $\omega_{P}=\mu \omega_{0}$ is inserted and (13) in (24). When $\Delta_{\delta}=0$, we fall back on the case studied in the previous section. An increase of the housing supply of floor space in the residential area of the $\operatorname{CBD}\left(\Delta_{\delta}\right)$ leads to expand the size of the CBD. The magnitude of this

\footnotetext{
${ }^{16}$ In Figure 2, we have $L=20, \omega_{P}=1, \delta=1$, and $R_{A}=1 / 4$, as well as $m=10$ and $\tau=1 / 10$. In Figure 3 , we have $L=20, \omega_{P}=1, \delta=1$, and $R_{A}=1 / 4$, as well as $m=2$ and $\tau=1$.
} 
effect is low when the opportunity cost of land reaches high values. A higher floor space per unit of land around the CBD induces a higher price paid per square meter and, in turn, a larger housing size when the opportunity cost of land $R_{A}$ is unchanged. Therefore, the CBD attracts more workers.

For more clarity, we focus on the configuration in which the wage rates in the CBD and the SBDs are equal $(\mu=1)$ so that $\widehat{z}=\frac{y_{p}}{3}+\frac{\Delta_{\delta}}{6 \tau R_{A} \omega_{0}}$. As expected, the size of the CBD grows when commuting costs decrease and the housing supply of floor space par unit of land around the CBD increases. We show in Appendix $\mathrm{F}$ that the equilibrium borders when the city is monocentric and polycentric are expressed as follows

$$
y_{M}\left(\Delta_{\delta}\right)=\frac{1+\Delta_{\delta}}{4 R_{A}^{2}} \frac{L / m}{1+\Gamma}
$$

and

$$
y_{P}\left(\Delta_{\delta}\right)=\frac{1}{4 R_{A}^{2}} \frac{L / m}{1+\Gamma / 3} \frac{3+\Delta_{\delta}}{3},
$$

respectively. It is straightforward to check that a polycentric city exists $\left(z\left[\Delta_{\delta}, y_{P}\left(\Delta_{\delta}\right)\right]<\right.$ $y_{P}\left(\Delta_{\delta}\right)$ ) if and only if $\Gamma>\Delta_{\delta}$ (see Appendix F). In addition, when the decentralization of jobs is possible, the city limit moves outward when the city becomes polycentric $y_{P}\left(\Delta_{\delta}\right)>y_{M}\left(\Delta_{\delta}\right)$ and $y_{P}\left(\Delta_{\delta}\right) / y_{M}\left(\Delta_{\delta}\right)$ increases with $\Gamma$ (see Appendix $\mathrm{F}$ ). Hence, our main results discussed in the previous section hold as the city border increases with job decentralization. For the same reasons detailed in Section 3, the effects of a relocation of jobs farther away from the CBD on commuting distances are ambiguous.

Notice also that, without pollution externality $(\zeta=0)$, the change in private welfare is still positive when the city becomes polycentric when the wage rate does not vary in the city (as shown in the previous section). Indeed, we have

$$
V_{P}(\zeta=0)-V_{M}(\zeta=0)=\omega_{0} \tau y_{M}\left(\Delta_{\delta}\right)\left\{1-\frac{z\left[\Delta_{\delta}, y_{P}\left(\Delta_{\delta}\right)\right]}{y_{M}\left(\Delta_{\delta}\right)}\right\}>0
$$

where $z\left[\Delta_{\delta}, y_{P}\left(\Delta_{\delta}\right)\right]<y_{M}\left(\Delta_{\delta}\right)$ when $\Gamma>\Delta_{\delta}$. As a consequence, the private welfare increases when the economy shifts from the monocentric to a polycentric structure even though the housing supply of floor space per unit of land around the CBD increases. Indeed, the maximum distance traveled by an individual working in the CBD declines when jobs relocate in the periphery of the city. However, the gain in private welfare is low when housing supply around the CBD is high. Hence, for the same reasons reported in Section 3, the effects of jobs decentralization on welfare are ambiguous as the city limit increases.

Hence, the spatial extension of the city remains the critical variable to reduce transportrelated pollution. Improvements in vertical extension of cities without controlling for their horizontal extension are likely insufficient to reduce transport-related urban pollution. Even though some empirical evidence suggests that more skyscrapers might be desirable for achieving more sustainable cities (Larson and Yezer, 2015; Larson et al., 2012), ${ }^{17}$ there are some reasons to remain cautious. Compact city policies, by reforming inappropriate building densities (e.g., building height restrictions, see Bertaud and Brueckner, 2005), could be a further

\footnotetext{
${ }^{17}$ Glaeser (2009) wrote: "To save the planet, build more skyscrapers"
} 
key priority in order to enable vertical extension (Glaeser, 2011; Suzuki et al., 2013) but should be coordinated with new infrastructure financing schemes for copying with increased local demand. Borck (2016) provides a theoretical but deep analysis of how vertical extension (building skyscrapers) could impact energy uses (coming from commuting and housing) and GHG emissions in a monocentric city. He shows that Floor-Area Ratio (FAR) limits can potentially decrease total emissions. On the one hand, FAR limits (i.e., limits to vertical extension in the inner city) lead to urban sprawl and therefore to increasing commuting distances (and of GHG emissions). But on the other hand, it induces increased competition for inner city land and raises housing prices, which consequently reduces total demand for housing (which decreases GHG emissions stemming from housing). The total effect of FAR limits is therefore not trivial, and vertical extension may not be the ultimate solution for promoting more sustainable cities.

\subsection{Endogenous wage}

In the previous sections, we have assumed that wages in the CBD and subcenters are exogenous, unlike Fujita and Ogawa (1982) and Lucas and Rossi-Hansberg (2002). We implicitly consider that wage rate does not adjust to a change in the size of labor markets. For example, an increase in the size of CBD $(\widehat{z})$ implies a higher mass of individuals working in the CBD and could impact the wage rates prevailing in the CBD and subcenters. We check if our main results hold when wages are endogenous.

We assume that firms produce a homogeneous good and labor is the only production factor. Our setting can easily be extended to the case of firms producing a differentiated good under monopolistic competition and using capital. Let $\Pi_{i}$ be the profit earned by a firm producing in the $\mathrm{CBD}$ if $i=0$ and in the $\mathrm{SBD}$ if $i=s$ given by

$$
\Pi_{i}=p Q_{i}-\omega_{i} T_{i}
$$

where $p$ is the output price, $T_{i}$ is the total amount of time units used by the firm and $Q_{i}$ is the output size with $Q_{i}=\mathbf{A}_{i} T_{i}^{\gamma}, \mathbf{A}_{i} \geq 1$ and $\gamma \leq 1$. As in Lucas and Rossi-Hansberg (2002), we consider that the marginal productivity of labor is non increasing and $\mathbf{A}_{i}$ is a productivity term that reflects an external effect on production which is specific to each business district (CBD and subcenters). The externality acts as a multiplier. Firms locating in the CBD benefits from a more efficient environment that takes the concrete form of a productivity drop $\mathbf{A}_{0}>\mathbf{A}_{s}=1$. According to Baum-Snow and Pavan (2012), agglomeration economies arise mainly within the central city even if, due the development of new information and communication technologies, their scope has spread within the city. We may then interpret $\mathbf{A}_{0}$ as follows: the stronger the agglomeration economies in the central city, the higher value of $\mathbf{A}_{0}$.

No wage bargaining. We first consider there is no wage negotiation. Under this configuration, maximizing (26) with respect to working time $T_{i}$ implies the following labor demand:

$$
p \mathbf{A}_{i} \gamma T_{i}^{\gamma-1}=\omega_{i}
$$


so that $\Pi_{i}=(1-\gamma) p \mathbf{A}_{i} T_{i}^{\gamma}=(1-\gamma)\left[p \mathbf{A}_{i}\right]^{\frac{1}{1-\gamma}}\left[\gamma / \omega_{0}\right]^{\frac{\gamma}{1-\gamma}}$ where we have inserted (27) in (26). In equilibrium, $\Pi_{0}=\Pi_{s}$ implies

$$
\omega_{0}=\mathbf{A}_{0}^{\frac{1}{\gamma}} \omega_{s}
$$

so that $\mu=\omega_{s} / \omega_{0}=\mathbf{A}_{0}^{-1 / \gamma}$. Hence, the wedge between the wage rates in the inner city and in the subcenters depends on the magnitude of agglomeration economies $\mathbf{A}_{0}$ and scale diseconomies $\gamma$. As a result, our results hold except that we have $\mathbf{A}_{0}^{-1 / \gamma}$ instead of $\mu$. ${ }^{18}$

Wage bargaining. We now consider that firms and workers bargain bilaterally over the wage rate. Let $\beta \in[0,1]$ denote the worker's bargaining power. We assume that $\beta$ is common to all matches. The firm and the worker negotiate a wage rate. ${ }^{19}$ Wages are determined by bilateral bargaining between employer and each worker separately in the spirit of Stole and Zwiebel (1996a, 1996b) (and Aumann and Shapley, 1974). The bargaining solution of Stole and Zwiebel generalizes the Nash solution to a setting with diminishing returns. Firms and workers bargain over the surplus generated by their employment relationship. Wages are determined by continuous bargaining between the firm and its employees. The firm's outside option is to produce with one fewer worker while the worker's outside option is given by her/his reservation utility which equal to the utility reached by a farmer (denoted $v_{A}$ ). The firm bargains individually with its entire workforce, treating each as marginal. Note that the marginal decision only involves an infinitely small time unit of labor as working time is a continuous variable. As in Stole and Zwiebel (1996a, 1996b), the firm pay the same wage rate (per time unit) to all its workers even though it is individually bargained. Hence, because of symmetry of firms, the wage rate prevailing in each business district is identical.

The surplus accruing from a successful match is split between the employee and the firm. The worker's surplus is equal to $\omega_{i} \ell_{i}(x)+1 /[4 R(x)]-v_{A}$ with $i=0, s, \ell_{0}(x)=1-\tau x$, and $\ell_{s}(x)=1-\tau\left|x-z_{p}\right|$. The firm's surplus is equal to the marginal increase in the firm's profit associated with an additional unit of labor time given by $\partial \Pi_{i} / \partial T_{i}=p \partial Q_{i} / \partial T_{i}-\omega_{i}-T_{i} \partial \omega_{i} / \partial T_{i}$ with $i=0, s$. Then, we solve the usual Nash-sharing rule

$$
\beta\left(p \frac{\partial Q_{i}}{\partial T_{i}}-\omega_{i}-T_{i} \frac{\partial \omega_{i}}{\partial T_{i}}\right)=(1-\beta)\left[\omega_{i} \ell_{i}(x)+\frac{1}{4 R(x)}-v_{A}\right]
$$

where $\beta$ is the index of the bargaining power of workers or, equivalently,

$$
\omega_{i}=\frac{(1-\beta)}{\ell_{i}(x)+\beta\left[1-\ell_{i}(x)\right]}\left[v_{A}-\frac{1}{4 R(x)}\right]+\frac{\beta}{\ell_{i}(x)+\beta\left[1-\ell_{i}(x)\right]}\left(\frac{\partial \Pi_{i}}{\partial T_{i}}-T_{i} \frac{\partial \omega_{i}}{\partial T_{i}}\right)
$$

The wage is a weighted average of two terms. The first term is the contribution of the outside option of the worker and land rents to his wage. As expected, higher prices of land imply higher wage rates. The second term is the contribution of working labor of a worker to the profit of the firm, taking into account that if the worker quits job, this also influence the wage

\footnotetext{
${ }^{18}$ Note that labor market clearing yields $N_{0} T_{0}=m \int_{0}^{\widehat{z}} \Delta_{0}(x) \ell_{0}(x) \mathrm{d} x$ where $N_{0}$ is the number of producers in the CBD and $T_{0}=\left(\mathbf{A}_{0} \gamma / \omega_{0}\right)^{1 /(1-\gamma)}$ as well as $N_{s} T_{s}=\int_{\widehat{z}}^{y} \Delta_{s} \ell_{s}(x) \mathrm{d} x$ where $N_{s}$ is the number of producers in the SBD and $T_{s}=\left(\gamma / \omega_{s}\right)^{1 /(1-\gamma)}$. We have $T_{0} / T_{s}=\mathbf{A}_{0}^{\frac{-1}{\gamma}}<1$.

${ }^{19}$ We consider there is no search cost for finding better matches.
} 
rate of other employees of the firm. This equation shows that the wage negotiated depends on employment $T_{i}$, chosen before the wage.

As Stole and Zwiebel show, the solution to this differential equation (28) is the generalized Shapley value. Since we have $\omega_{i} \ell_{i}(x)+[4 R(x)]^{-1}=\omega_{i} \ell_{i}(\widehat{z})+[4 R(\widehat{z})]^{-1}$ in equilibrium, regardless of the residential location of workers hired by a firm set up in the CBD, the solution to the differential equation (28) is given by

$$
\omega_{i}=\frac{(1-\beta)}{\ell_{i}(\widehat{z})+\beta\left[1-\ell_{i}(\widehat{z})\right]}\left[v_{A}-\frac{1}{4 R(\widehat{z})}\right]+\frac{\gamma \beta}{1-\beta+\beta \gamma} \frac{p \mathbf{A}_{i} T_{i}^{\gamma}}{T_{i}} .
$$

Note also that our wage equation takes a similar form as in other papers using the StoleZwiebel framework, such as Acemoglu and Hawkins (2014), Cahuc et al., (2008) and Elsby and Michaels (2013). Unlike those authors, we consider land rents and commuting costs in the wage equation. Using (29), the profit of firm reaches

$$
\Pi_{i}^{*}=p \mathbf{A}_{i} T_{i}^{\gamma} \frac{1-\beta}{1-\beta+\beta \gamma}-\frac{(1-\beta)}{\ell_{i}(\widehat{z})+\beta\left[1-\ell_{i}(\widehat{z})\right]}\left[v_{A}-\frac{1}{4 R(\widehat{z})}\right] T_{i}
$$

Labor demand $T_{i}^{*}$ is such $\partial \Pi_{i}^{*}\left[\omega_{i}\left(T_{i}\right)\right] / \partial T_{i}=0$. Inserting $T_{i}^{*}$ in (29) yields

$$
\omega_{i}^{*}=\frac{1}{\ell_{i}(\widehat{z})+\beta\left[1-\ell_{i}(\widehat{z})\right]}\left[v_{A}-\frac{1}{4 R(\widehat{z})}\right]
$$

so that

$$
\mu^{*}=\frac{\omega_{s}^{*}}{\omega_{0}^{*}}=\frac{1-(1-\beta) \tau \widehat{z}}{1-(1-\beta) \tau(y-\widehat{z}) / 2}
$$

with $\mu^{*}<1$ as long as $z>y / 3$ and $\partial \mu^{*} / \partial \widehat{z}<0$ and $\partial \mu^{*} / \partial \tau>0$. A higher share of workers working in the CBD (higher $\widehat{z}$ ) increases the relative wage rate in the CBD. According to (14), $\widehat{z}$ decreases with $\mu$. Under endogenous wages, $\mu$ increases with $\widehat{z}$ so that relationship between $\widehat{z}$ and $\mu$ remains negative. In addition, higher commuting costs raise the relative wage rate in the SBD making the city polycentric more likely. Hence, even if wages react to a change in urban form, our main results hold.

\subsection{Role of modal choice and congestion}

Our model assumes that the utility function depends on a negative externality $E$ in which the carbon emission per unit of distance $\epsilon$ does not vary. As a result, we leave aside the role of population density in carbon dioxide emissions generated by the level of traffic congestion and the commuting mode (Grote et al., 2016; Barth and Boriboonsomsin, 2008). For example, the impact of modal choices on carbon emissions in cities can be substantial, as the use of private cars is the major source of energy consumption, given that private cars are the most widespread mode choice among inhabitants living in low-density urban areas (Breheny, 1995; Rode et al., 2014). In particular, higher urban density yields lower levels of car use and more efficient public transportation systems. Therefore, public policies aiming at promoting bigger secondary business districts may conflict with the objective of lower emissions within the city, as a larger CBD provides a denser and a more energy-efficient public transportation system. 
Further, our framework disregards carbon emissions stemming from travel speed. We have assumed that travel speed does not vary within the city (our model captures only an average speed). The travel speed in a site depends on traffic congestion within it, i.e., on the number of commuters using the same road simultaneously. The high density of vehicles in a site forces users to reduce their average speed, as maximum road capacity is reached (Small and Verhoef, 2007; Rao and Rao, 2012). Barth and Boriboonsomsin (2008) highlight a $U$-shaped relationship between carbon emissions and average speed on road segments. When road users suffer from hypercongestion near the city center, carbon emissions are very high because of "stop and go" driving. Hence, a polycentric city would be able to reduce these high levels of road congestion in sites close to the CBD by lowering traffic density near the CBD.

Clearly, additional works are needed to better understand how modal choice and traffic congestion modify the relationship between urban form and social welfare. However, it is quite obvious that travel speed for road vehicles and the number of roads directly connected to the CBD still play a key role.

\section{Conclusion}

There is a wide consensus regarding implementing new spatial organizations of big cities among politics and urban planners. However, the debate remains complex. Questions regarding the feasibility and the acceptability of these policies and their efficiency remain open. Our paper brings several insights about possible urban policies. We have studied the relationship between urban design, commuting flows, transport-related pollution and welfare in order to assess whether a polycentric city might be a desirable configuration from the viewpoints of economic and ecological outcomes. In our framework, job decentralization within big cities has two opposing effects. On the one hand, we have the direct benefits of the value of induced travel savings for an unchanged residential location. On the other hand, job decentralization modifies residential choice, as land rents decrease on average. Indeed, lower land prices shift the demand for housing upward so that the city border moves outward. As the spatial extension of the city increases, commuting flows and transport-related emissions grow. These indirect costs may be important and, in realistic situations, may be considerably larger than the direct benefits, as suggested by empirical evidence (Veneri, 2010). Hence, a polycentric city is not necessarily the most desirable urban topology to promote. Actually, close scrutiny must be paid to the interplay between the housing demand, travel speed, transportation network structure, and urban pollution stemming from commuting flows. More importantly, the spatial extension of cities remains a critical variable to curb transport-related urban pollution.

Our work highlights the need for a cautious approach to implement policies that would guarantee the sustainable development of a city. This paper also demonstrates the significant role of housing demand on urban structure, which could help in evaluating the efficiency of urban policies. As underlined in Cho and Choi (2014), the desirability of urban forms remains largely a matter of debate. 


\section{References}

AASHTO, (2013). Commuting in America 2013: The National Report on Commuting Patterns and Trends - Brief 2. The role of commuting in overall travel. May 2013, Washington, DC. 24 p.

Acemoglu, D., and Hawkins W. (2014). Search with Multi-Worker Firms. Theoretical Economics. 9: 583-628.

Aguilera, A. (2005). Growth in commuting distances in French polycentric metropolitan areas: Paris, Lyon and Marseille. Urban Studies. 42: 1537-1547.

Alonso, W. (1964). Location and land use: Toward a general theory of land rent. Cambridge University Press. 204 p.

Anas, A., Arnott, R. and Small, K.A. (1998). Urban spatial structure. Journal of Economic Literature. 36: 1426-1464.

Angel, S., Sheppard S.C., and Civco, D.L. (2005). The Dynamics of Global Urban Expansion. Transport and Urban Development Department, The World Bank. Washington D.C., September 2005.

Anas, A., and Kim, I. (1996). General equilibrium models of polycentric urban land use with endogenous congestion and job agglomeration. Journal of Urban Economics. 40: $232-256$.

Arnott, R. J. (1979). Unpriced transport congestion. Journal of Economic Theory. 21(2): 294-316.

Barth, M., and Boriboonsomsin, K. (2008). Real-world carbon dioxide impacts of traffic congestion. Transportation Research Record: Journal of the Transportation Research Board. 2058: 163-171.

Baum-Snow, N., and Pavan, R. (2012). Understanding the city size wage gap. The Review of Economic Studies. 79(1): 88-127.

Bento, A. M., Cropper, M. L., Mobarak, A. M., and Vinha, K. (2005). The effects of urban spatial structure on travel demand in the United States. Review of Economics and Statistics. 87(3): 466-478.

Bertaud, A., and Brueckner, K. (2005). Analyzing building-height restrictions: predicted impact and welfare costs. Journal of Urban Economics. 35: 109-125.

Bertaud, A., Lefèvre, B., and Yuen, B. (2011). GHG emissions, urban mobility, and morphology: A hypothesis. Cities and Climate Changes. 87-123.

Birol, F. (2007). World Energy Outlook. OECD/IEA. 663 p.

Borck, R. (2016) Will skyscrapers save the planet? Building height limits and urban greenhouse gas emissions. Regional Science and Urban Economics. 58: 13-25.

Borck, R., and Brueckner, J. K. (2016). Optimal Energy Taxation in Cities. CESifo working paper 5711.

Breheny, M. (1995). The compact city and transport energy consumption. Transactions of the Institute of British Geographers. 81-101.

Brueckner, J. K. (2011). Lectures on Urban Economics. MIT Press. 283 p.

Burgalassi, D., and Luzzati, T. (2015). Urban spatial structure and environmental emissions: A survey of the literature and some empirical evidence for Italian NUTS 3 regions. Cities. 49: 134-148. 
Cahuc, P., Marque, F., and Wasmer, E. (2008). "A theory of wages and labor demand with intra-firm bargaining and matching frictions." International Economic Review. 49, 943972.

Calwell, C. (2010). Is efficient sufficient. The case for shifting our emphasis in energy. European Council for an Energy Efficient Economy. 29 p.

Cavailhès, J., Gaigné, C. , Tabuchi, T. and Thisse J.-F. (2007). Trade and the structure of cities. Journal of Urban Economics. 62: 383-404.

CGDD, (2010). La mobilité des Français, panorama issu de l'enquête nationale transports et déplacements 2008. La Revue du CGDD. Décembre 2010, Paris. 228 p.

EEA, (2007). Transport and environment: on the way to a new common transport policy, vol. EEA. Report No. 1/2007 of TERM 2006: indicators tracking transport and environment in the European Union. European Environment Agency. 44 p.

Elsby, M. and Michaels R. (2013). Marginal jobs, heterogeneous firms, and unemployment flows. American Economic Journal: Macroeconomics. 5: 1-48.

Floater, G., Rode, P., Robert, A., Kennedy, C., Hoornweg, D., Slavcheva, R. and Godfrey, N. (2014): Cities and the New Climate Economy: the transformative role of global urban growth. New Climate Economy Cities Paper 01. LSE Cities. London School of Economics and Political Science. 61 p.

Fujita M. and Ogawa H. (1982). Multiple equilibria and structural transition of nonmonocentric urban configurations. Regional Science and Urban Economics. 12(2): 161-196.

Gaigné C., S. Riou and J.-F. Thisse (2012). Are compact cities environmentally friendly? Journal of Urban Economics. 72: 123-136.

Giuliano, G., and Small, K. A. (1993). Is the journey to work explained by urban structure?. Urban Studies. 30: 1485-1500.

Glaeser, E.L., 2009. Green cities, brown suburbs. City Journal. 19(1): 50-55.

Glaeser, E. (2011). Triumph of the city: How our greatest invention makes US richer, smarter, greener, healthier and happier. Pan Macmillan.

Glaeser, E. L., and Kahn, M. E. (2010). The greenness of cities: carbon dioxide emissions and urban development. Journal of Urban Economics. 67(3): 404-418.

Goulden, M., Riley T., and Dingwall, R. (2014). Beyond 'predict and provide': UK transport, the growth paradigm and climate change. Transport Policy. 32: 139-147.

Grote, M., Williams, I., Preston, J., and Kemp, S. (2016). Including congestion effects in urban road traffic $\mathrm{CO}_{2}$ emissions modelling: Do Local Government Authorities have the right options?. Transportation Research Part D: Transport and Environment. 43: 95-106.

Hickman, R., and Banister, D. (2014). Transport, Climate Change and the City. Routledge. $376 \mathrm{p}$.

Hoornweg, D., Bhada, P., Freire, M., Trejos, C. L., and Sugar, L. (2010). Cities and climate change: An urgent agenda. The World Bank, Washington, DC. 92 p.

Larson, W., Liu, F., and Yezer, A. (2012). Energy footprint of the city: Effects of urban land use and transportation policies. Journal of Urban Economics. 72(2): 147-159.

Larson, W., and Yezer, A. (2015). The energy implications of city size and density. Journal of Urban Economics. 90: 35-49.

Legras, S. and Cavailhès, J. (2016). Environmental performance of the urban form. Regional Science and Urban Economics. 59, 1-11. 
Levy, D., et Le Jeannic, T. (2011). Un habitant de pôle urbain émet deux fois moins de CO2 que la moyenne pour se rendre sûr son lieu de travail ou d'études. INSEE Première. 1357.

Litman, T. (2015). Analysis of Public Policies That Unintentionally Encourage and Subsidize Urban Sprawl. Victoria Transport Policy Institute. Supporting paper commissioned by LSE Cities at the London School of Economics and Political Science. 89 p.

Lucas Jr, R. E., and Rossi-Hansberg, E. (2002). On the internal structure of cities. Econometrica. $1445-1476$.

Næss, P., and Vogel, N. (2012). Sustainable urban development and the multi-level transition perspective. Environmental Innovation and Societal Transitions. 4: 36-50.

Overman, H., Puga, D., and Turner, M. (2008). Decomposing the Growth in Residential Land in the United States. Regional Science and Urban Economics. 38: 487-497.

Rao, A. M., and Rao, K. R. (2012). Measuring urban traffic congestion-a review. International Journal for Traffic and Transport Engineering. 2(4): 286-305.

Rode, P., Floater, G., Thomopoulos, N., Docherty, J., Schwinger, P., Mahendra, A., and Fang, W. (2014). Accessibility in Cities: Transport and Urban Form. NCE Cities Paper 03. LSE Cities. London School of Economics and Political Science. 61 p.

Small, K. A., and Verhoef, E. T. (2007). The economics of urban transportation. Routledge. $276 \mathrm{p}$.

Sorell, S. (2007). The Rebound Effect: an assessment of the evidence for economy-wide energy savings from improved energy efficiency. UK Energy Research Centre. 108 p.

Stole, Lars A. and Zwiebel J. (1996a). Intra-firm bargaining under non-binding contracts. Review of Economic Studies. 63: 375-410.

Stole, Lars A. and Zwiebel J. (1996b). Organizational design and technology choice under intrafirm bargaining. American Economic Review. 86: 195-222.

Storper, M. (2013). Keys to the City: How Economics, Institutions, Social Interaction, and Politics Shape Development. Princeton University Press (July 2013).

Suzuki, H., Cervero, R., and Luchi, K. (2013). Transforming cities with transit: Transit and land-use integration for sustainable urban development. World Bank Publications. The World Bank. Washington, D.C. 205 p.

Timothy, D. and W.C. Wheaton (2001). Intra-urban wage variation, employment location and commuting times. Journal of Urban Economics. 50: 338-366.

United Nations (2014). Department of Economic and Social Affairs, Population Division. World Urbanization Prospects: The 2014 Revision, Highlights (ST/ESA/SER.A/352). 32 p.

Veneri, P. (2010). Urban polycentricity and the costs of commuting: evidence from italian metropolitan areas. Growth and Change. 41(3): 403-429.

Xue, L. K., Wang, T., Gao, J., Ding, A. J., Zhou, X. H., Blake, D. R., ... and Zhang, Q. Z. (2014). Ground-level ozone in four Chinese cities: precursors, regional transport and heterogeneous processes. Atmospheric Chemistry and Physics. 14(23): 13175-13188.

Zheng, S., Wang R., Glaeser E. and Kahn M. (2011). The greenness of China: household carbon dioxide emissions and urban development. Journal of Economic Geography. 11(5): $761-792$. 


\section{Appendix}

A. The equilibrium border with a monocentric city. The population constraint is given by

$$
m \int_{0}^{y} l(x) \mathrm{d} x=L .
$$

Solving (9) by using (8) leads to

$$
m \int_{0}^{y} \frac{\delta}{h(x)} \mathrm{d} x=L
$$

Trivial calculations show that

$$
\begin{aligned}
\int_{0}^{y} \frac{\delta}{h(x)} \mathrm{d} x & =\int_{0}^{y} \frac{4 \delta R_{A}^{2}}{\left[\delta-4 \omega_{0} \tau(y-x) R_{A}\right]^{2}} \mathrm{~d} x=\frac{4 \delta R_{A}^{2}}{4 \omega_{0} \tau R_{A}}\left[\frac{-1}{\delta-4 \omega_{0} \tau(y-x) R_{A}}\right]_{0}^{y} \\
& =\frac{4 \delta R_{A}^{2}}{4 \omega_{0} \tau R_{A}}\left(\frac{1}{\delta-4 t y R_{A}}-\frac{1}{\delta}\right)=\frac{4 R_{A}^{2} y}{\delta-4 \omega_{0} \tau y R_{A}} .
\end{aligned}
$$

Using the population constraint and $\delta=1$, we obtain

$$
y_{M}=\frac{L / m}{4 R_{A}\left(R_{A}+\omega_{0} \tau L / m\right)} .
$$

Accounting for the monetary costs of commuting and $\delta \neq 1$ does not qualitatively change our results. Indeed, considering $t(x)=t x$ with $t>0$ in the budget constraint and $\delta \neq 1$ leads to

$$
y_{M}(t>0, \delta)=\frac{\delta}{4 R_{A}} \frac{L / m}{R_{A}+\left(\omega_{0} \tau+t\right) L / m} .
$$

B. Commuting in a monocentric city. The total distance traveled by workers within the monocentric city is given by

$$
C_{M}=m \int_{0}^{y_{M}} x l(x) \mathrm{d} x .
$$

Inserting $l(x)=1 / h(x),(8)$, and (10) in $C_{M}$ leads to

$$
\begin{aligned}
C_{M} & =m \int_{0}^{y_{M}} \frac{4 R_{A}^{2} x}{\left[1-4 \omega_{0} \tau(y-x) R_{A}\right]^{2}} \mathrm{~d} x \\
& =\frac{m}{4 \omega_{0}^{2} \tau^{2}}\left[\ln \left(1-4 \omega_{0} \tau R_{A} y_{M}\right)^{-1}-4 \omega_{0} \tau R_{A} y_{M}\right] \\
& =\frac{m}{4 \omega_{0}^{2} \tau^{2}}\left[\ln \left(1+\frac{\omega_{0} \tau L}{m R_{A}}\right)-\frac{\omega_{0} \tau L}{m R_{A}+\omega_{0} \tau L}\right]>0 .
\end{aligned}
$$

Equivalently, we have

$$
C_{M}=\frac{m}{4 \omega_{0}^{2} \tau^{2}}\left[\ln (1+\Gamma)-\frac{\Gamma}{1+\Gamma}\right]
$$


with

$$
\Gamma \equiv \frac{\omega_{0} \tau L}{m R_{A}}
$$

Trivial calculations show that

$$
\operatorname{sign} \frac{\mathrm{d} C_{M}}{\mathrm{~d} \tau}=\operatorname{sign}\left[-(1+\Gamma)^{2} \ln (1+\Gamma)+\Gamma+\frac{3}{2} \Gamma^{2}\right]<0
$$

as the term in brackets is equal to zero when $\Gamma=0$ and decreases when $\Gamma$ increases. In addition, we have

$$
\operatorname{sign} \frac{\mathrm{d} C_{M}}{\mathrm{~d} m}=\operatorname{sign}\left[(1+\Gamma)^{2} \ln (1+\Gamma)-\Gamma(1+2 \Gamma)\right]
$$

where the term in brackets is equal to zero when $\Gamma=0$ and is positive when $\Gamma>0$.

C. Change in housing size when the city becomes polycentric. We compare the demand for housing for a city border $y$ that remains unchanged when the city is polycentric and monocentric. We show that housing size increases when the city moves from a monocentric configuration to a polycentric configuration. Using (16) and (8), we have

$$
h_{0}(x)-h(x)=\omega_{0} \tau(y-\widehat{z})>0
$$

for all $x \in[0, \widehat{z}]$. In addition, for all $x \in\left[\widehat{z}, z_{P}\right]$,

$$
\begin{aligned}
h_{P}(x)-h(x) & =\omega_{0} \tau(y-x)-\omega_{P} \tau\left(\frac{y-\widehat{z}}{2}-z_{P}+x\right) \\
& =\omega_{0} \tau(y-x)-\omega_{P} \tau(x-\widehat{z}) \\
& =\omega_{0} \tau[y-x(1+\mu)+\mu \widehat{z}]>0 .
\end{aligned}
$$

Indeed, under this configuration, the maximum value reached by $x$ is $z_{P}=\left(\widehat{z}+y_{P}\right) / 2$. As a consequence, the minimum value of the term in brackets is positive because

$$
\begin{aligned}
y_{P}-z_{p}(1+\mu)+\mu \widehat{z} & =y_{P}-\frac{\widehat{z}+y_{P}}{2}(1+\mu)+\mu \widehat{z} \\
& =\left(y_{P}-\widehat{z}\right)\left(\frac{1-\mu}{2}\right)>0 .
\end{aligned}
$$

Last, for all $x \in\left[z_{P}, y\right]$, we obtain

$$
\begin{aligned}
h_{P}(x)-h(x) & =\omega_{0} \tau\left(y_{P}-x\right)-\omega_{P} \tau\left(\frac{y_{P}-\widehat{z}}{2}-x+z_{P}\right) \\
& =\left(\omega_{0}-\omega_{P}\right) \tau\left(y_{P}-x\right) \geq 0
\end{aligned}
$$


D. The city border and commuting flows when the city is polycentric. The population constraint implies

$$
\int_{0}^{\widehat{z}} \frac{1}{h_{0}(x)} \mathrm{d} x+\int_{\widehat{z}}^{y_{P}} \frac{1}{h_{P}(x)} \mathrm{d} x=\frac{L}{m} .
$$

Because of the symmetry around the SBD, we have

$$
\int_{\widehat{z}}^{y_{P}} \frac{1}{h_{P}(x)} \mathrm{d} x=2 \int_{z_{P}}^{y_{P}} \frac{1}{h_{P}(x)} \mathrm{d} x
$$

with $h_{P}(x)=4\left[\frac{1}{4 R_{A}}-\omega_{0} \tau\left(y_{P}-x\right)\right]^{2}$ when $x>z_{P}$. Hence, the population constraint is given by

$$
\int_{0}^{\widehat{z}\left(y_{P}\right)} \frac{1}{h_{0}(x)} \mathrm{d} x+2 \int_{\widehat{z}\left(y_{P}\right)}^{z_{P}\left(y_{P}\right)} \frac{1}{h_{P}(x)} \mathrm{d} x=\frac{L}{m}
$$

or, equivalently,

$$
\begin{aligned}
\frac{R_{A}}{\omega_{0} \tau}\left[\frac{-1}{1-4 \omega_{0} \tau\left(y_{P}-x\right) R_{A}}\right]_{0}^{\widehat{z}\left(y_{P}\right)}+2 \frac{R_{A}}{\mu \omega_{0} \tau}\left[\frac{1}{1-4 \mu \omega_{0} \tau\left[x-\widehat{z}\left(y_{P}\right)\right] R_{A}}\right]_{\widehat{z}\left(y_{P}\right)}^{z_{P}\left(y_{P}\right)} & =\frac{L}{m} \\
\frac{4 R_{A}^{2} \widehat{z}\left(y_{P}\right)}{1-4 \omega_{0} \tau \widehat{z}\left(y_{P}\right) R_{A}}+2 \frac{4\left[z_{P}\left(y_{P}\right)-\widehat{z}\left(y_{P}\right)\right] R_{A}^{2}}{1-4 \mu \omega_{0} \tau\left[z_{P}\left(y_{P}\right)-\widehat{z}\left(y_{P}\right)\right] R_{A}} & =\frac{L}{m}
\end{aligned}
$$

Using the expression of $z_{P}\left(y_{P}\right)$, we obtain

$$
\frac{\widehat{z}\left(y_{P}\right)}{1-4 \omega_{0} \tau \widehat{z}\left(y_{P}\right) R_{A}}+\frac{y_{P}-\widehat{z}\left(y_{P}\right)}{1-2 \mu \omega_{0} \tau\left[y_{P}-\widehat{z}\left(y_{P}\right)\right] R_{A}}=\frac{1}{4 R_{A}^{2}} \frac{L}{m} .
$$

If $z=y_{P}$, then $y_{P}=y_{M}$ (we fall back on the monocentric configuration). Hence, equations (15) and (??) allow us to determine the equilibrium city limit and the equilibrium size of the CBD (in terms of jobs). As the population constraint is highly non-linear, the expression of the equilibrium city border is implicitly defined as follows:

$$
\frac{4 R_{A}^{2}\left(2-2 / \mu-\tau y_{P}\right)}{4 R_{A} \omega_{0}\left(\tau y_{P}+2 / \mu-2\right)-(2 / \mu+1)}+\frac{8 R_{A}^{2}\left(1 / \mu-\tau y_{P} / \mu-1\right)}{4 R_{A} \omega_{0}\left(\tau y_{P}+\mu-1\right)-(2 / \mu+1)}=\frac{\tau L}{m} .
$$

The total distance traveled by commuters is given by

$$
C_{p}(\mu)=m\left[\int_{0}^{\vec{z}(\mu)} \frac{x}{h_{0}(x)} \mathrm{d} x+2 \int_{z_{P}(\mu)}^{y_{P}(\mu)} \frac{x-z_{P}(\mu)}{h_{P}(x)} \mathrm{d} x\right],
$$

where

$$
\int_{0}^{\widehat{z}(\mu)} \frac{x}{h_{0}(x)} \mathrm{d} x=\frac{1}{4 \omega_{0}^{2} \tau^{2}}\left[\ln \left(1-4 R_{A} \omega_{0} \tau \widehat{z}(\mu)\right)^{-1}-4 R_{A} \omega_{0} \tau \widehat{z}(\mu)\right]
$$

and

$$
\int_{z_{P}(\mu)}^{y_{P}(\mu)} \frac{x-z_{P}(\mu)}{h_{P}(x)} \mathrm{d} x=\frac{1}{4 \mu^{2} \omega_{0}^{2} \tau^{2}}\left[\ln \left(1-2 R_{A} \mu \omega_{0} \tau\left[y_{P}(\mu)-\widehat{z}(\mu)\right]\right)^{-1}-2 R_{A} \mu \omega_{0} \tau\left[y_{P}(\mu)-z_{P}(\mu)\right]\right] .
$$


E. A monocentric city versus a polycentric city with $\omega_{0}=\omega_{P}$. If $\mu=1$, then $\widehat{z}=y_{P} / 3$ and $h_{0}(0)=h_{P}\left(z_{P}\right)=4\left[\frac{1}{4 R_{A}}-\omega_{0} \tau \frac{y_{P}}{3}\right]^{2}$ so that

$$
C_{P}=3 m \int_{0}^{\widehat{z}} \frac{x}{h_{0}(x)} \mathrm{d} x .
$$

Standard calculations yield

$$
\begin{aligned}
\int_{0}^{\widehat{z}} \frac{x}{h_{0}^{*}(x)} \mathrm{d} x & =\frac{1}{4 \omega_{0}^{2} \tau^{2}}\left[\ln \left(1-4 \omega_{0} \tau R_{A} \widehat{z}\right)^{-1}-4 \omega_{0} \tau R_{A} \widehat{z}\right] \\
& =\frac{1}{4 \omega_{0}^{2} \tau^{2}}\left[\ln \left(1+\frac{\omega_{0} \tau L}{3 m R_{A}}\right)-\frac{\omega_{0} \tau L / 3}{m R_{A}+\omega_{0} \tau L / 3}\right] .
\end{aligned}
$$

Hence, inserting $\widehat{z}=y_{P} / 3$ leads to

$$
C_{P}=\frac{3 m}{4 \omega_{0}^{2} \tau^{2}}\left[\ln \left(1+\frac{\omega_{0} \tau L}{3 m R_{A}}\right)-\frac{\omega_{0} \tau L / 3}{m R_{A}+\omega_{0} \tau L / 3}\right] .
$$

Notice that $C_{M}-C_{P} \equiv \Delta_{C}$ with

$$
\Delta_{C}=\frac{m}{4 \omega_{0}^{2} \tau^{2}}\left[\ln (1+\Gamma)-3 \ln \left(1+\frac{\Gamma}{3}\right)-\frac{1}{1+1 / \Gamma}+\frac{3}{1+3 / \Gamma}\right],
$$

in which $\Gamma \equiv \omega_{0} \tau L / m R_{A}$. It is straightforward to check that $\Delta_{C}=0, \partial \Delta_{C} / \partial \Gamma=0$,and $\partial^{2} \Delta_{C} / \partial^{2} \Gamma>0$ when $\Gamma=0$ and $\Delta_{C} \rightarrow-\infty$ when $\Gamma \rightarrow \infty$. In addition, we have

$$
\frac{\partial \Delta_{C}}{\partial \Gamma}=\frac{m}{4 \omega_{0}^{2} \tau^{2}} \frac{2 \Gamma\left(3-\Gamma^{2}\right)}{(1+\Gamma)^{2}(\Gamma+3)^{2}}
$$

so that $\Delta_{C}=0$ has a single solution when $\Gamma>0$, given by $\Gamma_{C}$ (with $\Gamma_{C} \simeq 3.78$ ). Hence, over the interval $\left(0, \Gamma_{C}\right), C_{M}>C_{P}$ where $\Delta_{C}$ achieves its maximum value when $\Gamma=\sqrt{3}$. Otherwise, $C_{M}<C_{P}$.

In addition, we have $V_{P}-V_{M} \equiv \Delta_{V}$ with

$$
\Delta_{V}=\frac{1}{4 R_{A}}\left[\frac{1}{1+1 / \Gamma}-\frac{1}{1+3 / \Gamma}\right]+\zeta \Delta_{C} .
$$

Some standard calculations show that $\Delta_{V}=0$ when $\Gamma=0$ and $\Delta_{V} \rightarrow-\infty$ when $\Gamma \rightarrow \infty$, and

$$
\frac{\partial \Delta_{V}}{\partial \Gamma}=\frac{\left(3-\Gamma^{2}\right)\left(\omega_{0} \tau+\zeta L\right)}{2(1+\Gamma)^{2}(\Gamma+3)^{2} R_{A} \omega_{0} \tau},
$$

with $\partial \Delta_{V} / \partial \Gamma>0$ when $\Gamma=0$. As a result, $\Delta_{V}=0$ has a unique solution over the interval $(0, \infty)$ given by $\Gamma_{V}>\Gamma_{C}$ and $V_{P}>V_{M}$ if and only if $\Gamma<\Gamma_{V}$. 
F. Housing supply discrepancy within a polycentric city. Land rents and housing demand. The equilibrium land rent is given by $R_{P}(x)=\max \left\{\Psi_{0}(x), \Psi_{P}(x), R_{A}\right\}$ where $\Psi_{0}(x)$ (resp., $\left.\Psi_{P}(x)\right)$ is the bid rent of individuals working in the CBD (resp., SBD). As $\partial V(x) / \partial x=0$, the bid rents around the CBD and the SBDs are given by, respectively,

$$
\Psi_{0}(x)=\frac{\left(1+\Delta_{\delta}\right) R_{A}}{1+\Delta_{\delta}-4 \omega_{0} \tau(\widehat{z}-x) R_{A}} \quad \text { and } \quad \Psi_{P}(x)=\frac{R_{A}}{1-4 \omega_{P} \tau\left[\frac{y_{P}-\widehat{z}}{2}-\left|z_{P}-x\right|\right] R_{A}} .
$$

The bid rents decrease with the distance to the business districts. The demand for housing of individuals working in the CBD is now given by $h_{0}(x)=\left(1+\Delta_{\delta}\right) /\left[4 R(x)^{2}\right]$. As a result, the equilibrium housing demands for individuals working in the CBD and in the SBD are respectively given by

$$
h_{0}(x)=4\left[\frac{1+\Delta_{\delta}}{4 R_{A}}-\omega_{0} \tau(\widehat{z}-x)\right]^{2} \quad \text { and } \quad h_{P}(x)=4\left[\frac{1}{4 R_{A}}-\omega_{P} \tau\left(\frac{y_{P}-\widehat{z}}{2}-\left|z_{P}-x\right|\right)\right]^{2} .
$$

City limit when the city is monocentric. The population constraint is now expressed as follows:

$$
\int_{0}^{y_{M}} \frac{1+\Delta_{\delta}}{h_{0}(x)} \mathrm{d} x=\frac{L}{m}
$$

or, equivalently,

leading to

$$
\frac{4 R_{A}^{2} y_{M}}{1+\Delta_{\delta}-4 \omega_{0} \tau R_{A} y_{M}}=\frac{L}{m} .
$$

$$
y_{M}\left(\Delta_{\delta}\right)=\frac{1+\Delta_{\delta}}{4 R_{A}^{2}} \frac{L / m}{1+\Gamma}
$$

City limit when the city is polycentric. The population constraint is now expressed as follows:

$$
\int_{0}^{\widehat{z}\left(y_{P}\right)} \frac{1+\Delta_{\delta}}{h_{0}(x)} \mathrm{d} x+2 \int_{\widehat{z}\left(y_{P}\right)}^{z_{P}\left(y_{P}\right)} \frac{1}{h_{P}(x)} \mathrm{d} x=\frac{L}{m}
$$

with $\widehat{z}=\frac{y_{P}}{3}+\frac{\Delta_{\delta}}{6 R_{A} \omega_{0}}$ when $\mu=1$ and $z_{P}\left(y_{P}\right)=\left(y_{p}+\widehat{z}\right) / 2$. Hence, we have

$$
\frac{4 R_{A}^{2} \widehat{z}\left(y_{P}\right)}{1+\Delta_{\delta}-4 \omega_{0} \tau \widehat{z}\left(y_{P}\right) R_{A}}+\frac{4 R_{A}^{2}\left[y_{P}-\widehat{z}\left(y_{P}\right)\right]}{1-2 \mu \omega_{0} \tau\left[y_{P}-\widehat{z}\left(y_{P}\right)\right] R_{A}}=\frac{L}{m} .
$$

leading to

$$
y_{p}\left(\Delta_{\delta}\right)=\frac{1}{4 R_{A}^{2}} \frac{L / m}{1+\Gamma / 3}\left(1+\frac{\Delta_{\delta}}{3}\right)
$$

so that

$$
\widehat{z}\left(\Delta_{\delta}\right)=\frac{1}{4 R_{A}^{2}} \frac{L / m}{1+\Gamma / 3} \frac{1}{3}\left(1+\Delta_{\delta}+\frac{2 \Delta_{\delta}}{\Gamma}\right)
$$

with $y_{P}\left(\Delta_{\delta}\right)-\widehat{z}\left(\Delta_{\delta}\right)>0$ if and only if $\Gamma>\Delta_{\delta}$.

Standard standard calculations reveal that $y_{P}\left(\Delta_{\delta}\right)>y_{M}\left(\Delta_{\delta}\right)$ as long as $\Gamma>\Delta_{\delta}$ and that

$$
\frac{y_{P}\left(\Delta_{\delta}\right)}{y_{M}\left(\Delta_{\delta}\right)}=\frac{1+\Gamma}{1+\Gamma / 3} \frac{3+\Delta_{\delta}}{3\left(1+\Delta_{\delta}\right)}
$$

increases with $\Gamma$. 